\title{
Managerial Overconfidence and the Value Adjustment Mechanism
}

\author{
Feng Xu \\ Accounting Department, Management School, Jinan University, Guangzhou, China \\ Email: leapbound1@163.com
}

How to cite this paper: $\mathrm{Xu}, \mathrm{F}$. (2018) Managerial Overconfidence and the Value Adjustment Mechanism. Open Journal of Accounting, 7, 93-106.

https://doi.org/10.4236/ojacct.2018.71007

Received: December 19, 2017

Accepted: January 21, 2018

Published: January 24, 2018

Copyright (C) 2018 by author and Scientific Research Publishing Inc. This work is licensed under the Creative Commons Attribution International License (CC BY 4.0).

http://creativecommons.org/licenses/by/4.0/

\begin{abstract}
Using the M \& A event of A-share listed companies from 2008 to 2013, which contains the value adjustment mechanism, as a sample, the paper is intended to explore the influence of managerial overconfidence on the performance growth rate and the relationship between the promise of profit growth rate and the performance of $\mathrm{M} \& \mathrm{~A}$. The results show that overconfident managers tend to accept higher performance growth rate, and this tendency is more obvious in private enterprises. The further study found that the higher the promise of profit growth rate, the better the performance of $\mathrm{M} \& \mathrm{~A}$., but when the overconfident manager makes a higher level of performance commitment, the market will react negatively. This mainly depends on the value adjustment mechanism to a certain extent, can alleviate the information asymmetry of both sides, and encourage the parties to participate in the process of integration after merger, but when overconfidence managers promise higher earnings growth, the investors tend to interpret it as manager's shortsighted behavior of lack of awareness of market risk.
\end{abstract}

\section{Keywords}

Managerial Overconfidence, Value Adjustment Mechanism, The Promise of Profit Growth Rate, Mergers and Acquisitions Performance

\section{Introduction}

In recent years, with the development and prosperity of the merger and acquisition market in our country, the M \& A mode is constantly being innovated. As an innovative exploration of $\mathrm{M} \& \mathrm{~A}$ model, the value adjustment mechanism is applied to an increasing number of $\mathrm{M} \& \mathrm{~A}$ cases. The value adjustment mechanism refers to the process of significant company restructure, in which the major business and the target business reached an agreement to facilitate the success of the transaction. 
Specifically, the target business promises to the major business on the performance that the underlying asset will achieve in a period of time in the future, if the business performance promised by the target business fails to reach the expected target, certain cash or share compensation will be paid by the target business.

As an important contractual arrangement, the value adjustment mechanism theoretically can mitigate the information asymmetry existing in the M \& A and effectively motivating the target company to actively participate in the M \& A integration process. It can alleviate the information asymmetry and agency problems existing in the process of mergers and acquisitions so as to effectively protect the legitimate rights and interests of the main parties and protect the interests of small and medium-sized investors [1]. However, during the actual operation of the system, there were problems of high performance commitment, high valuation and high default rate. The performance commitment of the acquired party often becomes the main basis for its asset pricing. The high commitment, high valuation and high default rate in the market are often blameworthy, which is the root cause that lies in the high performance commitment. This article attempts to start from the "three highs" problem and uses the behavioral finance perspective to explore the impact of management overconfidence on value adjustment mechanism and the economic consequences of high performance promises, so as to enrich the theoretical research on the value adjustment mechanism, and ultimately provide investors with a correct understanding of the value adjustment mechanism, and provide some reference for relevant departments to implement regulatory measures.

\section{Literature Review}

\subsection{Managers' Overconfidence and the $M$ \& A}

Due to the self-attribution bias, overconfident managers tend to recognize their own knowledge and skills more often and have higher expectations of their own environmental control. Billett and Qian (2008) discussed the history of mergers and acquisitions of individual managers and found that the market expected the earnings of the M \& A transactions based on the management's acquisition history and further reflected the changes in the stock market prices [2]. The article pointed out that the deviations from self-attribution will lead to management's overconfidence and the series of mergers and acquisitions implemented by overconfident managers. Finally, it will lead to the devaluation of the shareholder value. Fu Qiang and Fang Wenjun (2008), referring to the practice of Yu (2006), chose the business climate index published by the Bureau of Statistics as the proxy variable in measuring managers' overconfidence. The study found that overconfident managers tended to implement more frequent mergers and acquisitions. Wu Chaopeng, Wu Shinong and Zheng Fangkuo (2008) found that manager overconfidence will lead to a decline in the performance of a series of mergers and acquisitions; and when management can draw on effective experience from historical mergers and acquisitions, its dominant $\mathrm{M} \& \mathrm{~A}$ performance 
will gradually improve. Overall, domestic and foreign research found that overconfident managers will lead to higher frequency of mergers and acquisitions, higher M \& A premium and lower M \& A performance.

\subsection{The Value Adjustment Mechanism}

According to a case study, Gao Chuang et al. (2010) found that cash and equity all play an important role in protecting small and medium-sized investors in the selection of compensation methods. Among them, share buy-back is more effective than cash compensation in restraining large shareholders from carrying out high performance commitment and high valuation behavior, so as to effectively improve the performance of listed companies. Compared with the cash compensation, shares can more effectively protect the rights and interests of small and medium-sized investors. Zhang Bo and Fei Yiwen (2009) found that agreement on gambling is essentially a measure of protection for investors to protect their own income, which can restrain the moral hazard of management and effectively encourage management to realize the interests of investors. Through empirical research, Lv Changjiang et al. (2014) found that the value adjustment mechanism can enhance the benefits of target firms in the short term while enhancing the earnings of the major firms, which depends on signaling effects rather than stimulus effects. Through case studies, Liu Jianyong et al. (2014) found that the sample companies still distribute cash dividends to shareholders under the conditions of defaults. This may be the result of the transfer of profits by the main party in order to reduce the pressure on major shareholders' profit compensation, this behavior undermines the interests of public investors.

Overall, the research on management overconfidence and the $\mathrm{M} \& \mathrm{~A}$ at home and abroad has involved various areas such as $\mathrm{M} \& \mathrm{~A}$ decision-making, transaction pricing, $\mathrm{M} \& \mathrm{~A}$ performance and so on, and has formed a relatively complete research system, which is generally in line with the conclusions of the study. As a new thing in the $\mathrm{M} \& \mathrm{~A}$ market, the value adjustment mechanism has become more and more widely used in $\mathrm{M} \& \mathrm{~A}$ practice in our country. At present, the domestic literature has not yet explored the motivation of high commitment performance from the perspective of manager overconfidence, and the conclusion about the economic benefit analysis of the value adjustment mechanism has not been unified yet. The academic research on the new type of contractual arrangements is still in its infancy. This paper intends to fill the current literature gap by studying the impact of managers overconfidence on the growth rate of promised performance at the micro level, as well as the relationship between the growth rate of commitment performance and $\mathrm{M} \& \mathrm{~A}$ performance.

\section{Theoretical Analysis and Research Hypothesis}

\subsection{The Relationship between Managerial Overconfidence and Commitment Performance Growth Rate}

Overconfident managers tend to be more optimistic about their own knowledge 
and ability. And will have higher expectations for their ability to control the environment [3]. Malmendier and Tate (2008), overconfident managers overestimate the benefits of their dominant projects, thereby paying higher premiums to the target company, but causing a loss in the market profits of the major company. When studying the relationship between overconfidence and corporate risk taking [4]. Yu Minggui (2013) pointed out that managers with overconfidence also have higher willingness to take risks, and the improvement of risk appetite is conducive to promoting the optimal allocation of corporate resources and ultimately to the promotion of enterprises value.

The cultural tradition of centralization of power in China that lasted for thousands of years, and the current emerging and transitional economic environment, have provided an objective basis for overconfidence managers. The imperfect laws and regulations, the corporate governance structure and the incomplete supervision system further encourage managers' overconfidence. In the major assets reorganization with performance compensation commitment, the more management overconfidence, the more likely it is to overestimate the project revenue and underestimate the project risk. Due to the high degree of recognition of their own decision-making, they are usually optimistic that they will be successful. Accordingly, this paper proposes the following assumptions:

Hypothesis 1: Overconfidence managers tend to accept higher promised performance growth rates.

\subsection{The Influence of Property Rights on the Relationship between Managerial Overconfidence and Commitment Performance Growth}

State-owned listed companies are controlled by the state or local government. Relative to private enterprises, state-owned listed companies may obtain more and more comprehensive information on mergers and acquisitions due to the inclination of more government resources. Based on this, SOE managers may prefer to make more stable M \& A decision. Pan Hongbo (2008) pointed out: In our country, $\mathrm{M} \& \mathrm{~A}$ activities can serve as a way for the government to ease the employment problem and achieve political promotion. Due to non-economic factors, management may pay more attention to the achievement of policy goals and discouragement rather than the improvement of enterprise efficiency in $M$ \& A decision-making. Accordingly, this paper proposes the following assumptions:

Hypothesis 2: Overconfident managers of state-owned enterprises tend to accept a lower rate of promised performance growth than private-owned ones.

\subsection{Signal Transmission of Commitment Performance Growth Rate}

According to the signal theory, the stock price of the company will increase when the signals delivered by the insiders are "good news" (such as stock repurchase and dividend increase), and when the signals delivered by insiders are "bad news" (such as convertible bond redemption, re-issue), the stock price will 
fall. In research methods, the cumulative abnormal returns are generally used to measure the effect of signal transmission. This paper argues that in mergers and acquisitions, to determine the price is the process of bargaining by both parties, in which the key determinants of the consideration are the future performance of the underlying party's commitment and the promised performance is likely to be used to convey the relevant Company quality signal.

Typically, a financial behavior has a signal function requires two conditions: The first, the behavior must be implementation cost; The second, the cost differences between good companies and bad companies, and a worse company bears higher costs. Performance commitment can be a signal because of the fact it has the cost of implementation, that is, the present value of the possible future compensation amount; on the other hand, the performance compensation commitment costs will be higher for poor quality companies. Therefore, the value adjustment mechanism can deliver the quality signal of target party, and also to some extent reflect the expected performance to its future profitability [5]. When the parties are committed to a higher performance growth rate, they may send a positive forecast to the market for future M\&A performance. Therefore, the following hypothesis is proposed:

Hypothesis 3a: the higher the growth rate of the promised performance, the better the company's short-term market M\&A performance.

As the basis of the asset pricing of acquisition targets, the value adjustment mechanism has two sides in the case of information asymmetry. On the one hand, it may be a well-expected future performance to be delivered to the market with the asset of good quality. In this case, both parties agree on the future profitability of the underlying asset; on the other hand, the growth rate of high promised performance may be an excessive risk appetite caused by the deviation of the principal and the side managers on their own abilities, and even the growth rate of the promised performance of the underlying enterprises in order to obtain the high M \& A premium. May be reduced to the main and large shareholders and party conspiracy and conspiracy to emptied and undermine the interests of minority shareholders tools.

When non-overconfident managers accept a high growth rate of performance commitment, the market usually interprets it as a "good signal" that investors believe the promised performance at this time is a reflection of the real profitability of the underlying company and believes that through resources consolidation will yield positive performance; when overconfident managers accept higher performance commitment growth rate, the market usually interprets it as a "bad signal", that is, investors believe the performance growth promised by the subject party may be the result of CEO overestimating of their knowledge and ability and underestimating the project risk. Therefore, this paper proposes the following assumptions:

Hypothesis 3b: The higher the increasing rate of commitment performance accepted by overconfident managers, the worse the company's short-term market 
merger performance is.

\section{Research Design}

\subsection{Sample Selection}

This article chooses the M \& A event that adopts the value adjustment mechanism in non-financial enterprises from 2008 to 2013 as the initial sample. Based on the initial sample, the following screening will be conducted:

1) Remove $S T$ * and ST companies;

2) Remove samples that have not been audited or stopped by the CSRC;

3) Exclude samples with suspension period longer than 3 months before and after the merger announcement;

4) Exclude the acquisition of data samples cannot be obtained.

After the above screening, a total of 154 mergers and acquisitions with value adjustment mechanism were obtained. In the above data, data on value adjustment mechanism and underlying assets are collected manually from the corporate restructuring reports and interim announcements of each company, with the remaining data coming from the CSMAR and Wind databases.

\subsection{Variable Design}

1) Commitment Performance Growth Rate (GR) This article uses the geometric average annual net profit growth rate of the agreement terms as a measure of the growth rate of promised performance. If the net profit after deducting non recurring gains and losses of the target company in the next three years were $10,000,50,000$ and 100,000, the promised performance growth rate will be $\left[(100000 / 10000)^{\wedge}(1 / 2)-1\right]$. The geometric average growth rate is more consistent with the economic logic. For example, a variable increases from the initial 100 to 200 and finally down to 100 , According to the arithmetic average, the average growth rate was $25 \%$. Since the final value is equal to the initial value, the growth rate should apparently be $0 \%$, which corresponds to the result obtained from the geometric mean. Therefore, in the calculation of the average growth rate of finance and economy, the geometric average dominates and the geometric average growth rate also accords with the assumption of compound interest growth in economic and financial theories.

2) Cumulative abnormal return (CAR) This article uses the market adjustment method to calculate abnormal earnings of the company and examines the share price performance of the acquiring company within 7 trading days from 3 trading days prior to the first announcement of performance compensation agreement to 3 trading days after the merger and acquisition. Assuming $R_{i, t}$ represents the daily yield of stock I on $\mathrm{t}$ day, $R_{m, t}$ represents the market yield of $t$ day, and the calculation formula of the cumulative abnormal income CAR is as follows:

Stock $i$ Extraordinary Gain on Day t:

$$
A R_{i, t}=R_{i, t}-R_{m, t}
$$


Cumulative Abnormal Returns for T Days in $[1, T]$ for Stock $i$ :

$$
C A R_{i, t}=\sum_{i=1}^{n} A R_{i, t}
$$

3) Overconfidence (OC) At present, the indicators of managers' overconfidence at home and abroad are as follows: CEOs hold the right to exercise stock options; the mainstream media's assessment of CEO; the deviation of corporate profit forecast; the frequency of CEO's implementation of M \& A; Relative pay; historical performance of the enterprise; business climate index. Considering that the implementation rate of stock options of listed companies in our country is not high and the motivation proportion is small, and the standard of our country's media is less normative, the comments are more subjective. This article does not use the first two measures. The profit forecast of listed companies is affected by external environment and the impact of internal governance level, the third measurement method also has a big flaw; the enterprise climate index released by the National Bureau of statistics is a comprehensive reflection of the enterprise's operating conditions and macroeconomic environment. The management's estimate of the enterprise boom contains a positive reaction to the external environment to a certain extent, rather than a full sense of self-confidence.

Based on the methods of Yu Minggui (2013) and Jiang Wei (2010), this article attempts to use the general indicators composed of the general manager's gender, education, age, education background and the combination of director and general manager as the proxy variables of over-confident managers for the following specific reasons: a) Sex: Women are more cautious and conservative relative to men (Byrn et al., 1999) [6]. Therefore, if the general manager is male, the value is 1 , otherwise 0 ; b) Age: Senior age managers can evaluate their knowledge and ability more appropriately, and they are more inclined to avoid risks (Forbes, 2005) [7]. Therefore, if the general manager's age is less than the sample's mean, the value is 1, otherwise 0; c) Education: Managers are more likely to show overconfidence when they have a higher level of education because they are more confident of the correctness of judgments based on their own knowledge and have higher expectations of their environmental control (Schrand and Zechman, 2008) [8]. Therefore, if the general manager degree is bachelor degree or above, the value is 1, otherwise 0. d) Education Background: Ben-David et al. 2006 found that: managers with management education background may be more likely to believe their own risk control ability and ability to handle management affairs based on the management experience they possess. They may show a stronger tendency toward overconfidence [9]. If the manager has a management education background, with a value of 1 , otherwise 0 . e) The combination of director and general manager: The general manager who serves as the chairman of the board, is more likely to show heightened self-confidence by strengthening his knowledge of his own abilities (Billett, M.T. \& Qian, 2008) [2]. Therefore, if the managing director serves as chairman, the value is 1 , otherwise 0 .

This article measures managers' overconfidence through a comprehensive index determined by a single combination of managers. When managers have at least 
four of the above characteristics, they are defined as overconfidence, with an OC of 1 , otherwise 0 .

(4) the control variables (Control) This paper controls the following variables: capital structure:Lev (total liabilities/total assets), first shareholder's ownership: Shr1, the size of the company: Size (The natural logarithm of the asset), the connected transaction:GT ( 1 for a connected transaction, 0 otherwise), the nature of property right:State ( 1 for state-owned enterprises, 0 otherwise), excess cash holdings:FCF (the ratio of monetary funds to total assets less the industry average); Industry:Ind (dummy variable, industry classification according to SFC industry classification criteria, excluding financial and insurance sectors) and Year (dummy variable).

\subsection{Empirical Model}

To verify hypothesis 1 , construct a model (1) to examine the impact of managers overconfidence on the performance growth rate of mergers and acquisitions:

$$
\begin{aligned}
\mathrm{GR}= & \alpha_{0}+\alpha_{1} \mathrm{OC}+\alpha_{2} \mathrm{Shr} 1+\alpha_{3} \mathrm{GT}+\alpha_{4} \mathrm{State}+\alpha_{5} \mathrm{FCF}+\alpha_{6} \mathrm{ROA} \\
& +\alpha_{7} \mathrm{Size}+\alpha_{8} \mathrm{LEV}+\alpha_{9} \text { Yeari, } \mathrm{r}+\alpha_{10} \mathrm{INDi}, \mathrm{r}+\mathrm{e}
\end{aligned}
$$

To verify Hypothesis 2, construct a model (2) to examine the effect of property ownership on the relationship between manager overconfidence and growth rate of performance commitment in $\mathrm{M} \& \mathrm{~A}$ :

$$
\begin{aligned}
\mathrm{GR}= & \alpha_{0}+\alpha_{1} \mathrm{OC}+\alpha_{2} \mathrm{OC} * \text { State }+\alpha_{3} \mathrm{Shr} 1+\alpha_{4} \mathrm{GT}+\alpha_{5} \mathrm{State}+\alpha_{6} \mathrm{FCF} \\
& +\alpha_{7} \mathrm{ROA}+\alpha_{8} \mathrm{Size}+\alpha_{9} \mathrm{LEV}+\alpha_{10} \text { Yeari, } \mathrm{r}+\alpha_{11} \mathrm{INDi}, \mathrm{r}+\mathrm{e}
\end{aligned}
$$

This article further verifies the impact of the performance growth rate of promises on the market performance of short-term $\mathrm{M} \& \mathrm{~A}$ of listed companies, and builds the model:

$$
\begin{aligned}
\mathrm{CAR}= & \alpha_{0}+\alpha_{1} \mathrm{GR}+\alpha_{2} \mathrm{Shr} 1+\alpha_{3} \mathrm{GT}+\alpha_{4} \mathrm{State}+\alpha_{5} \mathrm{ROA}+\alpha_{6} \mathrm{FCF} \\
& +\alpha_{7} \mathrm{Size}+\alpha_{8} \mathrm{LEV}+\alpha_{9} \text { Yeari, } \mathrm{r}+\alpha_{10} \mathrm{INDi}, \mathrm{r}+\mathrm{e}
\end{aligned}
$$

To verify the promised performance growth rate and managers overconfidence $\mathrm{o}$ on the short-term $\mathrm{M} \& \mathrm{~A}$ market performance of listed companies, build the model:

$$
\begin{aligned}
\mathrm{CAR}= & \alpha_{0}+\alpha_{1} \mathrm{GR} * \mathrm{OC}+\alpha_{2} \mathrm{GR}+\alpha_{3} \mathrm{OC}+\alpha_{4} \mathrm{Shr} 1+\alpha_{5} \mathrm{GT}+\alpha_{6} \mathrm{State}+\alpha_{7} \mathrm{ROA} \\
& +\alpha_{8} \mathrm{FCF}+\alpha_{9} \mathrm{Size}+\alpha_{10} \mathrm{LEV}+\alpha_{11} \text { Yeari, } \mathrm{r}+\alpha_{12} \mathrm{INDi}, \mathrm{r}+\mathrm{e}
\end{aligned}
$$

\section{Empirical Analysis}

\subsection{Descriptive Statistics}

Descriptive statistics of the main variables in this paper are shown in Table 1. As can be seen from Table 1, the mean of overconfidence (OC) is 0.318 , indicating that $31.8 \%$ of executives in the sample data are overconfident and the mean of $\triangle \mathrm{ROA}$ is negative. This is in line with the current domestic and foreign research on $\mathrm{M} \& \mathrm{~A}$ performance The conclusion is consistent: the merger and acquisition will lead to the devaluation of the main business entity; the average value of the 
State property is 0.258 , indicating that $25.8 \%$ of the sample companies are stateowned enterprises; the average of the related-party transaction (GT) is 0.497 , This shows that nearly half of the sample data is related mergers and acquisitions.

Table 2 shows the correlation coefficient matrix of the major variables. From the table we can see that under the condition of not controlling other variables, overconfidence (OC) and promised performance growth rate (GR) are significantly positive at the level of $5 \%$. The relationship between the main variables needs to be put into the regression equation for further discussion. In this paper, Variance Expansion Factor (VIF) is used to test the existence of multicollinearity among the independent variables to verify the feasibility of the model. The VIF indices of seven variables GR, Shr1, State, GT, FCF, Lev and Size are: 1.06, 1.02, $1.03,1.62,1.06,1.62,1.09$. In general, VIF values above 10 indicate that there may be severe multicollinearity between the respective variables. From the results we can see that all the independent variables VIF values are less than 2 , and much less than 10, indicating that the collinearity between the respective variables weaker, the regression results using these independent variables with credibility.

Table 1. Descriptive statistics.

\begin{tabular}{ccccccc}
\hline variable & $\mathrm{N}$ & mean & $\max$ & $\min$ & $\mathrm{p} 50$ & $\mathrm{sd}$ \\
\hline GR & 155 & 0.233 & 1.067 & -0.169 & 0.186 & 0.196 \\
OC & 154 & 0.318 & 1 & 0 & 0 & 0.467 \\
CAR & 154 & 0.161 & 1.549 & -0.255 & 0.0833 & 0.304 \\
Shr1 & 154 & 34.91 & 86.49 & 7.833 & 31.88 & 15.60 \\
State & 155 & 0.258 & 1 & 0 & 0 & 0.439 \\
GT & 155 & 0.497 & 1 & 0 & 0 & 0.502 \\
FCF & 154 & 0.00585 & 1.012 & -0.623 & 0.0128 & 0.146 \\
Lev & 154 & 0.452 & 8.256 & 0.0533 & 0.331 & 0.756 \\
Size & 154 & 21.12 & 23.56 & 16.76 & 21.04 & 1.056 \\
\hline
\end{tabular}

Table 2. Correlation coefficient matrix.

\begin{tabular}{cccccccccc}
\hline & GR & OC & $\Delta$ ROA & Shr1 & State & GT & FCF & Lev & Size \\
\hline GR & 1 & & & & & & & \\
OC & $0.188^{* *}$ & 1 & & & & & & \\
SROA & 0.119 & -0.0250 & 1 & & & & & & \\
Shr1 & $-0.198^{* *}$ & -0.0290 & 0.0640 & 1 & & & & & \\
State & $-0.227^{* *}$ & -0.119 & -0.0930 & 0.00100 & 1 & & & & \\
GT & $-0.173^{* *}$ & -0.0980 & $0.185^{* *}$ & 0.00800 & $0.328^{* * *}$ & 1 & & & \\
FCF & -0.0330 & 0.0390 & -0.0720 & -0.0170 & -0.0250 & 0.0490 & 1 & & \\
Lev & 0.0970 & $0.142^{*}$ & -0.0170 & $-0.142^{*}$ & 0.113 & $0.244^{* * *}$ & $0.195^{* *}$ & 1 & \\
Size & $-0.176^{* *}$ & $-0.283^{* * *}$ & 0.0620 & $0.145^{*}$ & 0.0720 & -0.0160 & -0.128 & $-0.377^{* * *}$ & 1 \\
\hline
\end{tabular}




\subsection{Regression Analysis}

1) The relationship between managerial overconfidence and commitment performance growth rate.

Table 3 shows the regression results of manager overconfidence and commitment performance growth rate. The first column examines the impact of manager overconfidence on the performance growth rate of promises without controlling for other factors. The regression results show that the coefficient of OC is significantly positive at the level of 5\% (2.357), indicating that overconfident managers promise higher performance growth. The second column adds other control variables that affect the growth rate of performance. The overconfidence of managers is still positive at a level of $10 \%$ (1.965). This shows that there is still a significant and positive correlation between manager overconfidence and promised performance growth after controlling for other variables. This is consistent with the conclusion of Hypothesis 1 that overconfidence managers tend to accept higher promised performance growth rates.

2) The impact of property rights on the relationship between Managerial overconfidence and commitment performance growth rate.

The third column of Table 3 shows that after adding other control variables that affect the performance growth rate, the coefficients of overconfidence and property ownership are significantly negative at the level of $5 \%$. It shows that in state-owned enterprises, overconfident managers can significantly reduce the growth rate of promised performance, which is in line with the conclusion of

Table 3. Managers Overconfidence and Commitment Performance of the regression results.

\begin{tabular}{ccccccc}
\hline \multirow{2}{*}{ VARIABLES } & \multicolumn{2}{c}{ GR } & \multicolumn{2}{c}{ GR } & \multicolumn{2}{c}{ GR } \\
\cline { 2 - 7 } & $(1)$ & $\mathrm{T}$ & $(2)$ & $\mathrm{T}$ & $(3)$ & $\mathrm{T}$ \\
\hline OC & $0.0784^{* *}$ & $(2.357)$ & $0.0595^{*}$ & $(1.965)$ & $0.0836^{* *}$ & $(2.563)$ \\
OC*State & & & & & $-0.170^{*}$ & $(-1.876)$ \\
State & & & & & & \\
Shr1 & & & -0.0509 & $(-1.348)$ & -0.0267 & $(-0.675)$ \\
ROA & & & -0.158 & $(-0.762)$ & -0.0883 & $(-0.424)$ \\
GT & & & $-0.0658^{* *}$ & $(-2.082)$ & $-0.0574^{*}$ & $(-1.819)$ \\
FCF & & & $-0.236^{* *}$ & $(-2.204)$ & $-0.223^{* *}$ & $(-2.098)$ \\
Lev & & & -0.0178 & $(-0.734)$ & -0.0140 & $(-0.581)$ \\
Size & & & 0.00626 & $(0.398)$ & 0.00763 & $(0.490)$ \\
Constant & $0.206^{* * *}$ & $(10.97)$ & 0.521 & $(1.211)$ & 0.476 & $(1.116)$ \\
Year & Yes & Yes & Yes & Yes & Yes & Yes \\
Ind & Yes & Yes & Yes & Yes & Yes & Yes \\
Observations & 154 & & 154 & & 154 & \\
R-squared & 0.0289 & & 0.3497 & & 0.3625 & \\
\hline
\end{tabular}

t-statistics in parentheses; ${ }^{* *} \mathrm{p}<0.01,{ }^{* *} \mathrm{p}<0.05,{ }^{*} \mathrm{p}<0.1$. 
Hypothesis 2 that overconfident managers of state-owned enterprises tend to accept a lower rate of promised performance growth than private-owned ones.

3) The relationship between commitment performance growth rate and $M \&$ A performance.

The first column of Table 4 shows the regression results of the promised performance growth rate and M \& A short-term market performance. Under the control of other trading characteristics, the coefficient of promised performance growth rate is 0.288 , which is significantly positive at the level of $10 \%$, which means that the higher the promised performance growth rate, the better the performance of short-term market M \& A will be. This depends mainly on the value adjustment mechanism can convey the signal of the target company's quality to the market, and to a certain extent, it reflects the commitment level of the promised party for its future profitability. When the target company promises higher performance growth rates, it may be able to convey to the market a better expectation of the future performance about target company.

(4) Analysis of the regression result of committed performance growth and overconfidence in signal transmission.

The second column of Table 4 shows the regression results of the crossgrouping of manager overconfidence and promised performance growth on short-term market performance. The coefficient of overconfidence and commitment performance growth rate was significantly negative. This shows that

Table 4. Regression results of commitment performance growth and M \& A performance.

\begin{tabular}{ccccc}
\hline \multirow{2}{*}{ VARIABLES } & \multicolumn{3}{c}{ CAR } & \multicolumn{3}{c}{ CAR } \\
\cline { 2 - 5 } & $(1)$ & $(1.782)$ & $0.479^{* *}$ & $(2.398)$ \\
\hline GR & $0.288^{*}$ & & $-0.515^{*}$ & $(-1.659)$ \\
OC GR & & 0.125 & $(1.312)$ \\
OC & & & -0.000141 & $(-0.0823)$ \\
Shr1 & -0.000486 & $(-0.285)$ & 0.0137 & $(0.196)$ \\
State & 0.0217 & $(0.316)$ & $0.143^{* *}$ & $(2.401)$ \\
GT & $0.149^{* *}$ & $(2.509)$ & 0.0187 & $(0.0486)$ \\
ROA & 0.152 & $(0.402)$ & 0.00154 & $(1.457)$ \\
Ratio & 0.00163 & $(1.545)$ & 0.0830 & $(0.412)$ \\
FCF & 0.0148 & $(0.0752)$ & -0.0120 & $(-0.268)$ \\
Lev & 0.00242 & $(0.0551)$ & $-0.0698^{* *}$ & $(-2.383)$ \\
Size & $-0.0717^{* *}$ & $(-2.500)$ & 0.948 & $(1.174)$ \\
Constant & 1.081 & $(1.354)$ & Yes & Yes \\
Year & Yes & Yes & Yes & Yes \\
Ind & Yes & Yes & 153 & \\
Observations & 153 & & 0.1252 & \\
Adj R-squared & 0.1198 & & &
\end{tabular}

$\mathrm{t}$-statistics in parentheses; ${ }^{* * *} \mathrm{p}<0.01,{ }^{* *} \mathrm{p}<0.05,{ }^{*} \mathrm{p}<0.1$. 
compared to the non-overconfident managers, overconfidence managers who accept higher performance growth rate will send "bad" signal to the market. That is, investors think the commitment performance growth rate promised by the target party may be lower than the actually achievable performance growth under the conditions of information asymmetry. At this point, the over-confident managers' acceptance of promised performance growth based on cognitive bias is the result of their overestimation of their knowledge and ability and underestimation of project risk.

\subsection{Robustness Test}

1) Adjustment of promised performance growth rate: In the previous article, geometric average method was used to measure the growth rate of promised performance. Considering that the geometric averaging method only focuses on the performance levels at both ends of the promised period, it is suitable for the case that the development process consistently rises or falls. The geometric average law is not comprehensive enough when the performance of the underlying asset fluctuates sharply during the commitment period. This paper further uses the arithmetic average method to calculate the growth rate of commitment performance. The regression result also supports the conclusion of Hypothesis 1 and Hypothesis 2 that managers who overconfidence in mergers and acquisitions tend to accept higher performance promises. In private enterprises this tendency is more obvious.

2) Adjustment of $M \& A$ performance: In the previous section, we use the cumulative abnormal returns of 7 days before and after the first announcement day to measure M \& A performance. This paper further adopts cumulative abnormal returns of 11 days before and after the first announcement day to verify the relationship between the growth rate of commitment performance and $\mathrm{M} \&$ A performance. The regression results still support the conclusion of Hypothesis 3 that the higher the promised performance growth rate, the better the M \& A performance.

3) Regression method adjustment: For robustness, we further use the fixed-effects model to regress the sample. The result is still found that overconfident managers tend to accept higher performance growth rate, and this tendency is more obvious in private enterprises. The further study found that the higher the promise of profit growth rate, the better the performance of M \& A., but when the overconfident manager makes a higher level of performance commitment, the market will react negatively.

\section{Conclusions and Countermeasures}

Using the M \& A event of A-share listed companies from 2008 to 2013, which contains the value adjustment mechanism, as a sample. The paper is intended to explore the influence of managerial overconfidence on the performance growth rate and the relationship between the promise of profit growth rate and the 
performance of $\mathrm{M} \& \mathrm{~A}$. The results show that overconfident managers tend to accept higher performance growth rate, and this tendency is more obvious in private enterprises. The further study found that the higher the promise of profit growth rate, the better the performance of M \& A., but when the overconfident manager makes a higher level of performance commitment, the market will react negatively.

With the continuous reform of China's economic restructuring, mergers and acquisitions are increasingly becoming one of the important strategic measures to promote the upgrading of China's industrial structure and development of enterprises. The original design intention of value adjustment mechanism is to regulate the pricing of mergers and acquisitions assets through the mandatory punishment, thereby enhancing the efficiency of mergers and acquisitions. However, the system still has many problems, such as: high commitment, high pricing, performance goals are difficult to complete and so on. How to effectively regulate the trading behavior in the $\mathrm{M} \& \mathrm{~A}$ market and guide the entities to effectively use the value adjustment mechanism in mergers and acquisitions still requires the full cooperation of both the mergers and acquisitions, the regulatory agencies and the asset assessment agencies.

First of all, we should further perfect the information disclosure system of listed companies, conduct detailed and professional disclosure on the pricing process of the subject matter, details of the performance commitment signing, regular follow-up and fulfillment of the promised performance, etc.; Secondly, we should strengthen the supervision departments of the regulatory responsibility; Thirdly, we should regulate the evaluation and auditing of intermediary agencies, and punish intermediaries and their responsible persons that fail to diligently perform or even fraud for stopping related business, and even revoke qualifications.

\section{References}

[1] Cadman, B., Carrizosa, R. and Faurel, L. (2014) Economic Determinants and Information Environment Effects of Earnouts: New Insights from SFAS 141(R). Journal of Accounting Research, 52, 37-74. https://doi.org/10.1111/1475-679X.12036

[2] Billett, M.T. and Qian, Y.M. (2008) Are Overconfidence CEOs Born or Made? Evidence of Self-Attribution Bias from Frequent Acquirers. Management Science, 54, 1037-1051. https://doi.org/10.1287/mnsc.1070.0830

[3] Hayward, M. and Hambrick, D. (1997) Explaining the Premiums Paid for Large Acquisitions: Evidence of CEO Hubris. Administrative Science Quarterly, 42, 103-127. https://doi.org/10.2307/2393810

[4] Maimendier, U. and Tate, G. (2008) Who Makes Acquisitions? CEO Overconfidence and the Market's Reaction. Journal of Financial Economics, 89, 20-43. https://doi.org/10.1016/j.jfineco.2007.07.002

[5] Lukas, E., Reuer, J.J. and Welling, A. (2012) Earnouts in Mergers and Acquisitions: A Game-Theoretic Option Pricing Approach. European Journal of Operational Research, 223, 256-263. https://doi.org/10.1016/j.ejor.2012.05.017

[6] Bymes, J.P., Miller, D.C. and Schafer, W.D. (1999) Gender Differences in Risk Tak- 
ing; a Meta-Analysis. Psychological Bulletin, 125, 367-383.

https://doi.org/10.1037/0033-2909.125.3.367

[7] Forbes, D. (2005) Are Sane Entrepreneur More Overconfident than Others. Journal of Business Venturing, 20, 623-640. https://doi.org/10.1016/j.jbusvent.2004.05.001

[8] Schrand, C.M. and Zechman, S.L.C. (2012) Executive Overconfidence and the Slippery Slope to Financial Misreporting. Journal of Accounting and Economics, 53, 311-329. https://doi.org/10.1016/j.jacceco.2011.09.001

[9] Ben-David, I., Graham, J.R. and Harvey, C.R. (2006) Managerial Overconfidence and Corporate Policies. NEBR Working Paper, No: 13711. 